\title{
Preparation and Methylene Blue Adsorption Capacity of HDPE/PVA Foaming Composites
}

Fenghong Li ( $\nabla$ lfhby@aliyun.com)

Shenyang University of Technology https://orcid.org/0000-0002-4697-4703

\section{Zhe Wang}

Shenyang University of Technology

\section{Pengzhen Li}

Shenyang University of Technology

\section{Wei Da}

Shenyang University of Technology

\section{Weisi Lv}

Shenyang University of Technology

\section{Keyun Guo}

Shenyang University of Technology

\section{Feihong Huang}

Shenyang University of Technology

\section{Research Article}

Keywords: High density polyethylene, Polyvinyl alcohol, Methylene blue, Removal efficiency

Posted Date: December 29th, 2021

DOI: https://doi.org/10.21203/rs.3.rs-1195710/v1

License: (c) (1) This work is licensed under a Creative Commons Attribution 4.0 International License.

Read Full License 


\title{
Preparation and methylene blue adsorption capacity of HDPE/PVA foaming composites
}

\author{
Li Fenghong, Wang Zhe, Li Pengzhen, Da Wei, Lv Weisi, Guo Keyun, Huang Feihong, Wei Xiang, Guo Lin \\ Shenyang University of Technology, College of petroleum and chemical engineering, Liaoyang, Liaoning \\ Province, China \\ The corresponding author: Li Fenghong, lfhby@aliyun.com \\ ORCID: 0000-0002-4697-4703
}

\begin{abstract}
High density polyethylene (HDPE) and polyvinyl alcohol (PVA) are blended with maleic anhydride grafted amorphous-alpha olefin copolymer as the compatibilizer. The effects of different raw material ratio and the content of compatibilizer and foaming agent on the mechanical properties of the material are studied. It is found that the increasing content of PVA added to HDPE has a negative effect on the properties of the composites. The compatibility and mechanical properties are improved after adding MAH-g-APAO and the most appropriate addition amount is $4 \%$. Foaming agent can make the material lightweight but will decrease the mechanical properties of the material. The composites have a good effect on the removal of methylene blue (MB). Through the experiment, it is found that the initial concentration of $\mathrm{MB}$ and adsorption time will also influence the adsorption. The experiment to explore the influence of $\mathrm{pH}$ value and temperature of solution on the removal efficiency shows that alkaline environment and high temperature can promote the removal of MB. At $343.15 \mathrm{~K}$, the adsorption capacity $\left(\mathrm{q}_{\mathrm{e}}\right)$ reaches $2.08 \mathrm{mg} \cdot \mathrm{g}^{-1}$. Using the composites to remove dye has the advantages of environmental protection, simple operation and easy recycling. It has broad application prospects in the field of dye wastewater treatment.
\end{abstract}

Key words: High density polyethylene; Polyvinyl alcohol; Methylene blue; Removal efficiency 


\section{Introduction}

High density polyethylene (HDPE) is a high-yield material with compact structure, high crystallinity and fine mechanical properties [1-5]. Moreover, it has replaced materials such as metal and wood which are expensive or hard to be formed. It now is widely used to make pipes due to its characteristics of heat resistance, cold resistance and high stability. Its good electrical insulation is often used as the insulation layer and sheath of wires and cables [6-7]. Polyvinyl alcohol (PVA) is a material with high surface activity, high biocompatibility and film-forming ability [8-10]. In addition, it is non-toxic and harmless and can be degraded by specific microorganisms [11-12]. PVA has broad application prospects under the social background of green development [13]. However, a large number of H-bonds within and between PVA molecules lead to its high melting point. When PVA is melted, part of it has been decomposed, which makes it difficult to melt process PVA [14-15]. HDPE is inserted between PVA molecular chains as a plasticizer when we blend them two. Nonpolar HDPE molecules block PVA and avoid the formation of H-bonds between PVA molecular chains. This weakens the force between PVA molecular chains, reduces the crystallinity and increases the mobility of molecules. The melting temperature of PVA is decreased and then PVA can be processed by melting [16-19]. Meanwhile Maleic anhydride grafted amorphous $\alpha$-olefin copolymer (MAH-g-APAO) was used as the compatibilizer to improve the blending effect. The mechanism of plasticization and compatibilization is shown in Fig. 1.

Methylene blue (MB) is a solid powder at room temperature, which is a commonly used cationic dye for cotton, wool textiles and silk [20]. But MB is toxic and difficult to biodegrade, and will even cause poisoning or death to aquatic organisms when its concentration increases to a certain level in water [21-22]. Years recently, due to the rapid development of the textile industry and the printing or dyeing industry, dye wastewater discharged by the dye factories has increased day by day, and the destruction to the environment has become increasingly serious. Therefore, the research on the wastewater treatment of MB has become increasingly important [23]. For the time being, the main methods of wastewater treatment are adsorption, oxidation, membrane separation and flocculation precipitation method. Among them, adsorption is widely used because of its low cost, simple operation, eco-friendliness and easy recovery [24-25]. Polymer foaming materials have great potency in the removal of dye due to their porous internal structure and large specific surface area [26]. As shown in Fig. 2, PVA brings a large amount of hydroxyl to form H-bonds between the nitrogen atoms [27]. At the same time, MAH-g-APAO dehydrates and condenses with PVA, forming the $\mathrm{C}=\mathrm{O}$ which can link with the $\pi$ electronic in the form of $\mathrm{n}-\pi$ interaction on aromatic rings of MB [28-29], which also makes contribution to the removal of MB. In this paper, HDPE/PVA composites was 
used to investigate the effects of various factors on MB removal by changing the initial dye concentration, $\mathrm{pH}$ value and temperature. 


\section{Experimental}

\section{Materials}

PVA was produced by Sinopec Shanghai Petrochemical Co., Ltd, HDPE was from PetroChina Co., Ltd, foaming agent was from Foshan Ouxi Chemical Co., Ltd, MAH -g-APAO was prepared in the laboratory, MB was from Tianjin Beichenfangzheng Reagent Factory.

\section{preparation of HDPE/PVA}

HDPE and PVA were blended with foaming agent and compatibilizer at $160{ }^{\circ} \mathrm{C}$ in the mixer (SU-70C, Changzhou SuYan Technology Co., Ltd). By changing the ratio of HDPE to PVA, the content of the compatibilizer and foaming agent, the influence of various factors on mechanical properties of materials were explored, the formulas are as shown in Tab. 1, Tab. 2 and Tab. 3. After granulation, HDPE/PVA composites foaming material was prepared by plate vulcanizing machine (XLB-DY, Qingdao Huabo Machinery Technology Co., Ltd) at $160{ }^{\circ} \mathrm{C}$.

Tab.1. Formulas with different ratio of HDPE to PVA

\begin{tabular}{cccc}
\hline Mixture ID & HDPE/PVA & Foaming agent $(\%)$ & Compatibilizer agent $(\%)$ \\
\hline $1-1$ & $10 / 0$ & 6 & 6 \\
$1-2$ & $9.5 / 0.5$ & 6 & 6 \\
$1-3$ & $9 / 1$ & 6 & 6 \\
$1-4$ & $8 / 2$ & 6 & 6 \\
$1-5$ & $7 / 3$ & 6 & 6 \\
\hline
\end{tabular}

Tab.2. Formulas with different content of compatibilizer agent

\begin{tabular}{cccc}
\hline Mixture ID & HDPE/PVA & Foaming agent $(\%)$ & Compatibilizer agent $(\%)$ \\
\hline $2-1$ & $7 / 3$ & 6 & 0 \\
$2-2$ & $7 / 3$ & 6 & 1 \\
$2-3$ & $7 / 3$ & 6 & 2 \\
$2-4$ & $7 / 3$ & 6 & 3 \\
$2-5$ & $7 / 3$ & 6 & 4 \\
$2-6$ & $7 / 3$ & 6 & 5 \\
$2-7$ & $7 / 3$ & 6 & 6 \\
\hline
\end{tabular}

Tab.3. Formulas with different content of foaming agent

\begin{tabular}{cccc}
\hline Mixture ID & HDPE/PVA & Foaming agent $(\%)$ & Compatibilizer agent $(\%)$ \\
\hline $3-1$ & $7 / 3$ & 2 & 4 \\
$3-2$ & $7 / 3$ & 4 & 4 \\
$3-3$ & $7 / 3$ & 6 & 4
\end{tabular}




\begin{tabular}{llcc}
$3-4$ & $7 / 3$ & 8 & 4 \\
$3-5$ & $7 / 3$ & 10 & 4 \\
\hline
\end{tabular}

\section{Characterization}

The tensile and bending properties of samples were tested by the electronic universal testing machine (CMT, Shenzhen Nss Laboratory Equipment Co., Ltd). The tensile rate was set to $1 \mathrm{~mm} / \mathrm{min}$, the bending rate was set to 2 $\mathrm{mm} / \mathrm{min}$. Each sample was tested for three times and the average was taken as the tensile strength and bending strength of the sample.

The functional groups and chemical bonds of the samples were determined by Fourier transform infrared spectrometer (FT-IR) (TENSOR II, Bruker, Germany). The scanning range was from $500 \mathrm{~cm}^{-1}$ to $4000 \mathrm{~cm}^{-1}$.

MB solution of different concentrations were prepared, and the absorbance was tested by ultraviolet visible spectrophotometer (UV-2600, Shimadzu (Suzhou) Co., Ltd) to draw the concentration curve of MB solution. Taking the absorbance of MB solution into the concentration curve, the concentration of MB can be obtained.

The samples were cut into squares with side length of $5 \mathrm{~mm}$. Weigh $0.15 \mathrm{~g}$ of them as a group, and put one group into MB solution to test its removal efficiency. The calculation formula is as follows:

$\eta=\frac{\mathrm{C}_{0}-\mathrm{C}_{\mathrm{t}}}{\mathrm{C}_{0}} \times 100 \%$

where $\eta$ is the removal efficiency, $\mathrm{C}_{0}\left(\mathrm{~g} \cdot \mathrm{L}^{-1}\right)$ is the initial concentration of $\mathrm{MB}$ in water after adsorption.

Six groups of samples cut into squares $(0.15 \mathrm{~g}$ for each group) were added into $30 \mathrm{~mL} \mathrm{MB}$ solution with concentrations of $0.01 \mathrm{~g} \cdot \mathrm{L}^{-1}, 0.02 \mathrm{~g} \cdot \mathrm{L}^{-1}, 0.03 \mathrm{~g} \cdot \mathrm{L}^{-1}, 0.04 \mathrm{~g} \cdot \mathrm{L}^{-1}, 0.05 \mathrm{~g} \cdot \mathrm{L}^{-1}$ and $0.06 \mathrm{~g} \cdot \mathrm{L}^{-1}$ respectively. The removal efficiency after adsorption saturation was tested to explore the influence of the initial concentration of MB on the adsorption effect.

Put one group of samples cut into squares $(0.15 \mathrm{~g}$ for each group) into $30 \mathrm{~mL} \mathrm{MB}$ solution with the concentration of $0.02 \mathrm{~g} \cdot \mathrm{L}^{-1}$. The absorbance was tested every $2 \mathrm{~h}$ until it was saturated. The removal efficiency was calculated and then the curve of removal rate and contact time was drawn.

Five groups of samples cut into squares ( $0.15 \mathrm{~g}$ for each group) were selected and put into five groups of $30 \mathrm{~mL}$ MB solution with different $\mathrm{pH}$ value. The $\mathrm{pH}$ of $\mathrm{MB}$ solution was regulated to 5, 7, 9, 11, 13 respectively. The removal efficiency was calculated after adsorption saturation. The influence of $\mathrm{pH}$ value was studied.

Five groups of $30 \mathrm{~mL} \mathrm{MB}$ solution with the concentration of $0.01 \mathrm{~g} \cdot \mathrm{L}^{-1}$ were prepared. Adjusted their 
temperatures to $30{ }^{\circ} \mathrm{C}, 40{ }^{\circ} \mathrm{C}, 50{ }^{\circ} \mathrm{C}, 60{ }^{\circ} \mathrm{C}$ and $70{ }^{\circ} \mathrm{C}$ respectively. Then put one group of samples into each one. Tested the absorbance after adsorption saturation, and the influence of temperature on the removal efficiency of MB was obtained.

\section{Results and discussion}

\section{Analysis of mechanical properties}

It can be perceived from Fig. 3 (a) and Fig. 3 (b) that the tensile strength and bending strength both showed a downward trend with the increase of PVA content in the composites. The tensile strength decreased to 2.605 MPa from 10.606 MPa when the ratio of HDPE and PVA was 7/3. As for the bending strength, it decreased to 6.113 MPa from 14.505 MPa at the same change of ratio. This indicated that they have poor phase interface adhesion due to their different polarities of PVA and HDPE, which causes the poor compatibility between them. When the mechanical properties are tested, the interface becomes the concentrated stress point and breaks first, which leads to poor mechanical properties of the composites. The more phase interface formed between PVA and HDPE, the poorer the mechanical properties are.

Fig. 4 (a) showed that the overall trend of tensile strength of composites rose first and then fell with the increase of compatibilizer content. The tensile strength reached the highest point when the mass proportion of compatibilizer is 4\%, which is $4.367 \mathrm{MPa}$. As shown in Fig. 4 (b), the bending strength appeared an extremely similar trend with the tensile strength, it also reached the highest point for $8.562 \mathrm{MPa}$ when the compatibilizer is $4 \%$. This showed that when the compatibilizer content was low, the compatibility between HDPE and PVA was improved under the influence of compatibilizer content, the adhesion at the interface increased, so the mechanical properties increased. When the compatibilizer exceeded the required content, the compatibilizer became an additional phase, resulting in phase separation and reducing the mechanical properties of the composites.

Fig. 5 (a) and Fig. 5 (b) showed the influence of the content of foaming agent on the mechanical properties of the composites. Obviously, the foaming agent will weaken the mechanical properties of the composites. With the increase of foaming agent content, more bubbles were formed inside the composites, and the air pressure in the bubble hole kept increasing. The bubble wall was destroyed when the air pressure exceeded the bearing capacity of the bubble wall. Then the bubbles interconnected with other bubbles adjoining, resulting in the decrease of mechanical properties of the composites. 


\section{Analysis of FT-IR}

From Fig. 6, $3312 \mathrm{~cm}^{-1}$ is the absorption peak of -OH in PVA, $2914 \mathrm{~cm}^{-1}$ and $2847 \mathrm{~cm}^{-1}$ are the symmetrical stretching vibration peaks of $-\mathrm{CH}_{2}$ in $\mathrm{HDPE}$, and $1738 \mathrm{~cm}^{-1}$ is the $\mathrm{C}=\mathrm{O}$ brought by the MAH-g-APAO and the $\mathrm{C}=\mathrm{O}$ of vinyl acetate residue in PVA production process.

\section{Analysis of adsorption behavior of MB}

In the light of Lambert-Beer law:

$\mathrm{A}=\varepsilon \mathrm{bc}=\lg \frac{1}{\mathrm{~T}}$

it is obvious that the absorbance (A) is proportional to the concentration (C) when the absorption coefficient $(\varepsilon)$ and the thickness of the absorption layer (b) are fixed. Therefore, the concentration of MB in the solution can be calculated by the measured absorbance with the help of the concentration curve drawn. MB solution with different concentrations was prepared and its absorbance was tested. MB solution concentration curve is drawn as Fig. 7.

Fig. 7 indicated that the measured concentration curve is not a straight line. This is because when the solution concentration gets to a high level, the average distance between the absorption particles decreases. The refractive index will also change due to the rising of concentration, which will affect the absorption coefficient $\varepsilon$. Influenced by the refractive index and the interaction of the charge distribution between particles, their absorption coefficient $\varepsilon$ changes, resulting in the nonlinear relationship between the solution concentration and the absorbance Meanwhile, the light stability of MB at high concentration is poor, which leads to the light degradation of MB [30-31]. The concentration equation fitted is as follows:

$\mathrm{A}=-534.61 \times \mathrm{C}^{2}+66.69 \times \mathrm{C}+0.03$

where $\mathrm{A}$ is the absorbance, $\mathrm{C}$ is the concentration MB. $\mathrm{R}^{2}$ is 0.9988 , which shows that there is still a great correlation between the absorbance and concentration of MB even if MB solution is at a high concentration.

(1) Influence of initial MB concentrations on adsorption of MB

The removal Aefficiency of MB by the composites decreases as an overall trend with the increasing concentration of MB solution as shown in Fig. 8. When the concentration rose from $0.01 \mathrm{~g} \cdot \mathrm{L}^{-1}$ to $0.02 \mathrm{~g} \cdot \mathrm{L}^{-1}$, the removal efficiency increased slightly. This shows that under the prerequisite of keeping composites dosage changeless, appropriately increasing the dye concentration can improve the concentration gradient which is the driving force to promote $\mathrm{MB}$ molecules in solution to approach the composites and can make MB molecules have 
more opportunities to contact with the active adsorption sites inside the foaming composites, so the removal efficiency increased. But the adsorption of MB attached to the composites gets to be saturated when the dye concentration increases to a certain level, resulting in a decrease trend when the concentration of MB keeps rising.

(2) Influence of contact time on adsorption of MB

From Fig. 9, we see that the removal efficiency of MB increased rapidly at the beginning of adsorption. This is because there were many adsorption sites in the composites at the beginning. Then the pace of adsorption slowed down at the late stage of adsorption. Obviously as the contact time went on, the adsorption sites were gradually occupied, the active adsorption sites became scarce, and at last the rates of desorption and adsorption got to be equal and the adsorption capacity increased no more. In addition, after the active sites on the surface of the composites were all occupied, the left MB molecules waiting to be adsorbed needed to break through the resistance to contact with the active sites inside the composites. It is harder than the adsorption on the surface, which also leaded to the slowing down growth at the last of adsorption.

(3) Influence of $\mathrm{pH}$ value on adsorption of $\mathrm{MB}$

Fig. 10 demonstrated that the increasing $\mathrm{pH}$ value led to an increasing trend for the removal efficiency of MB. As the concentration of $\mathrm{H}^{+}$in the acid solution is high, $\mathrm{H}^{+}$will compete with MB for active adsorption sites [32]. The concentration of $\mathrm{H}^{+}$in the solution decreased with the $\mathrm{pH}$ value increased, the more active sites were free for MB.

(4) Influence of temperature on adsorption of MB

The influence of temperature on adsorption of MB was explored. Fig. 11 (a) shows the cross-section of the composites before and after adsorption at different temperatures. Fig. 11 (b) shows the color change of MB solution before and after adsorption. It can be demonstrated that with temperature rising, more MB molecules were tied to the composites, and the solution color became lighter, which means that hyperthermia may have a positive effect on the adsorption of MB. Noteworthily, the composites have a porous structure and MB molecules will not get too much resistance to get into the inside of the foaming composites.

Calculation equation of equilibrium adsorption quantity:

$q_{e}=\frac{\mathrm{C}_{0}-\mathrm{C}_{\mathrm{e}}}{m} \times \mathrm{V}$

where $\mathrm{q}_{\mathrm{e}}\left(\mathrm{mg} \cdot \mathrm{g}^{-1}\right)$ is the quantity of equilibrium adsorption of $\mathrm{MB}, \mathrm{C}_{0}\left(\mathrm{mg} \cdot \mathrm{L}^{-1}\right)$ is the initial concentration, $\mathrm{C}_{\mathrm{e}}$ $\left(\mathrm{mg} \cdot \mathrm{L}^{-1}\right)$ is the concentration at equilibrium, $\mathrm{m}(\mathrm{g})$ is the addition quantity of the composites, and $\mathrm{V}(\mathrm{L})$ is the solution volume.

Fig. 12 (a) was the equilibrium adsorption quantity at different temperatures, while Fig. 12 (b) was the removal 
efficiency at different temperatures.

It was clear in Fig. 12 that the equilibrium adsorption quantity and removal efficiency were both positively affected by raising temperature. The equilibrium adsorption quantity reached $2.08 \mathrm{mg} \cdot \mathrm{g}^{-1}$ and the removal efficiency reached $94.7 \%$ when it was set for $70{ }^{\circ} \mathrm{C}$.

The adsorption equilibrium constant $k_{d}$ at each temperature was calculated by: $K_{d}=\frac{q_{e}}{C_{e}}$. Fig. 13 was drawn with $\ln \mathrm{K}_{\mathrm{d}}$ and $1 / \mathrm{T}$.

Thermodynamic parameters are calculated as follows, $\ln \mathrm{K}_{\mathrm{d}}=-\frac{\Delta \mathrm{H}^{0}}{\mathrm{RT}}+\frac{\Delta \mathrm{S}^{0}}{\mathrm{R}}$

$\Delta \mathrm{H}_{0}$ is calculated to be $57.22 \mathrm{~kJ} \cdot \mathrm{mol}^{-1}$ by putting the slope of the fitted curve into the equation, indicating that the process is endothermic, and hyperthermia does benefit to the process. $\Delta \mathrm{S}_{0}$ is calculated to be $157.02 \mathrm{~J} \cdot \mathrm{mol}^{-1} \cdot \mathrm{K}^{-1}$ by putting the intercede of the fitted curve into the equation, indicating that the reaction is an entropy increase process. Before the MB was adsorbed by the composites, a large number of water molecules were attached to the surface of the composites. -MB molecule requires desorbing several water molecules, resulting in that the increased entropy caused by the desorption of water molecules exceeded the decreased entropy caused by the adsorption of MB, which made the entropy negative on the whole.

\section{Conclusion}

In this work, PVA and HDPE were blended to prepare the composites. However, due to the problem of compatibility, the mechanical properties of the composites decrease with the addition of PVA. The compatibility between PVA and HDPE can be enhanced by adding an appropriate amount of compatibilizer, and the mechanical properties of the composites can be enhanced to a certain extent.

In the respect of the adsorption of MB by the composites, the experimental data showed that low concentration MB was easier to be adsorbed than high concentration MB. As the contact time went on, the rising of removal efficiency was fast at the beginning and slowed down when it was about to reach adsorption equilibrium. The study on the influence of $\mathrm{pH}$ value showed that the composites had a better efficiency in alkaline environment. Set the adsorption progress of $\mathrm{MB}$ at 5 , it is found that hyperthermia is positive to the adsorption. When it rose to $343.15 \mathrm{~K}$, the adsorption capacity reaches $2.08 \mathrm{mg} \cdot \mathrm{g}^{-1}$. Differing from conventional dye wastewater purification methods, taking foaming composites to adsorb dye wastewater has a simpler process and is easier to be recycled. There is great potential for foaming composites in MB wastewater treatment. 


\section{Reference}

[1] Anu M.A., Savitha Pillai S.: Structure, Thermal, Optical and Dielectric Properties of $\mathrm{SnO}_{2}$ Nanoparticles-filled HDPE Polymer. J. Phys. Chem. Solids, Lett. Sect. 341, 114577 (2021) https://doi.org/10.1016/j.ssc.2021.114577

[2] Xia B., Xu W., Wang K., Huang Q., Liang W., Sun X.: Study of Mechanical Property and Cellular structure Based on the Controllable Crosslinking Polyethylene Foaming Materials. IOP Conf. Ser.: Mater. Sci. Eng. 544, 012058 (2019) https://doi.org/10.1088/1757-899X/544/1/012058

[3] Zhang Y., Wang X., Hou S.: Progress on Performance Improvement in the Recent of High Density $\begin{array}{llllll}\text { Polyethylene } \quad \text { Composites. } & \text { Plast. } & \text { Sci. Technol. 49, }\end{array}$ https://doi.org/10.15925/j.cnki.issn1005-3360.2021.05.025

[4] Lu W., Zhang Q., Zhou H., Liu C., Cai H.: Study on Thermal Stabilities and Mechanical Properties of Sweet Sorghum Slag/High Density Polyethylene Composites. Renewable Energy Resour. 39, 717-723 (2021) https://doi.org/10.13941/j.cnki.21-1469/tk.2021.06.002

[5] García E., Louvier Hernández J.F., Cervantes Vallejo F.J., Flores Martínez M., Hernández R., Alcaraz Caracheo L.A., Hernández Navarro C.: Mechanical, dynamic and tribological characterization of $\begin{array}{lllll}\text { HDPE/peanut shell composites. Polym. } & \text { Test. 98, } 107075\end{array}$ https://doi.org/10.1016/j.polymertesting.2021.107075

[6] Koffi A., Mijiyawa F., Koffi D., Erchiqui F., Toubal L.: Mechanical Properties, Wettability and Thermal Degradation of HDPE/Birch Fiber Composite. Polymer. 13, $1459 \quad$ (2021) https://doi.org/10.3390/polym13091459

[7] Huang X., Zhang J., Jiang P.: Thermoplastic Insulation Materials for Power Cables: History and Progress. High Voltage Eng. 44, 1377-1398 (2018) https://doi.org/10.13336/j.1003-6520.hve.20180430001

[8] Li F., Chen J., Xie D.: Thermal Processability of mPVA/PEG Composites. Plast. Sci. Technol. 49, 5-8 (2021) https://doi.org/10.15925/j.cnki.issn1005-3360.2021.02.002

[9] Hou Q., Wang X.: The effect of PVA foaming characteristics on foam forming. Cellulose. 24, 4939-4948 (2017) https://doi.org/10.1007/s10570-017-1452-1

[10] Li P., Li F., Shi Y., Da W., Wang Z., Jiang T., Chen L.: Research Progress of Polyvinyl Alcohol Foaming Materials. Eng. Plast. Appl. 49, 172-176 (2021)

[11] Wu Z.: Preparation and Properties of Biodegradable Polyvinyl Alcohol Composites. Master Thesis. Northwest Normal University. (2012)

[12] Zhang H., Liu B., Luo R.: Recent Advances in the Biodegradability of PVA and Its Derivative Material. J. Grad. Sch. Chin. Acad. Sci. 22, 657-666 (2005)

[13] Liu H., Shen D., Gou J.: Modification of Lignin/PVA Foam Materials. Packag. Eng. 38, $71-77$ (2017) https://doi.org/10.19554/j.cnki.1001-3563.2017.23.017

[14] Li K.: The Preparation, Structure and Properties of Poly(vinyl alcohol)/Starch Biodegradable Composite Materials. Master Thesis, Hunan University of Technology. (2013)

[15] Zhang J.: Studies on Melt-processing Properties of Polyvinyl Alcohol. Master Thesis, Hefei University of Technology. (2013)

[16] Fan H., Huang G., Xue X.: Modification Methods of Melt Processing of PVA. Synth. Fiber China. 15-17 (2006)

[17] Ma C., Lu C., Wu M., Guan Z., Li Y., Zhang J.: Phase Morphology and Dynamic Rheological Properties of PVA/HDPE/HDPE-g-MAH Blends. J. Funct. Polym. 29, 418-423 (2016) https://doi.org/10.14133/j.cnki.1008-9357.2016.04.007 
[18] Tang H.: Research Progress of Polyvinyl Alcohol Thermoplastic Processing. Chem. Eng. Des. Commun. 46, 85-86 (2020)

[19] Li F., Chen J., Shen H., Xie D.: Thermal Processability of mPVA/PEG Composites. Synth. Resin Plast. 38, 36-39 (2021) https://doi.org/10.19825/j.issn.1002-1396.2021.01.08

[20] Sun L., Sun Y., Li M., Yu B., Liu C., Wu J., Guo Z., Liu Y.: Study on Treatment of Methylene Blue Wastewater by Various Adsorbent Materials. Shandong Chem. Ind. 47, 197-198 (2018) https://doi.org/10.19319/j.cnki.issn.1008-021x.2018.14.082

[21] Kuang Y.: Adsorption of Methylene Blue and Cadmium Ions by Surfactant Modified Activated Carbon. Master Thesis, South China University of Technology. (2020) https://doi.org/10.27151/d.cnki.ghnlu.2020.003797

[22] Rafatullah M., Sulaiman O., Hashim R., Ahmad A.: Adsorption of Methylene Blue on Low-cost Adsorbents: a review. J. Hazard. Mater. 177, 70-80 (2010) https://doi.org/10.1016/j.jhazmat.2009.12.047

[23] Yang W., Zhang J., Yan M.: Advances in the Detection Methods and Metabolic Kinetics of Methylene Blue. J. Food Saf. Qual. 9, 2419-2425 (2018)

[24] Zhao Y., Ma L., Zhao K., Wu B., Yang W.: Adsorption of Methylene Blue Dye from Wastewater by Expanded Graphite Modified Using PVA. Chin. J. Environ. Eng. 9, 5709-5713 (2015)

[25] Umoren S. A., Etim U. J., Israe A. U.: Adsorption of Methylene Blue from Industrial Effluent Using Poly (vinyl alcohol). J. Mater. Environ. Sci. 4, 75-86 (2013)

[26] Fang Z.: Study on Treatment of Wastewater with Modified Polyurethane Foam. Master Thesis, Suzhou University of Science and Technology (2015).

[27] Song J., Han X., Huang L., Niu Y.: Preparation and Adsorption Properties of PVA / KHA / GG Porous Hydrogel. Appl. Chem. Ind. 50, 712-717 (2021) https://doi.org/10.16581/j.cnki.issn1671-3206.20201221.025

[28] Nguyen T. T., Hoang B. N., Van T. T., Van N. D., Nguyen T. D., Vo D. V. N.: Agar/Maltodextrin/Poly (vinyl alcohol) Walled Montmorillonite Composites for Removal of Methylene Blue from Aqueous Solutions. Surf. Interfaces. 26, 101410 (2021) https://doi.org/10.1016/j.surfin.2021.101410

[29] Siddiqa A. J., Chaudhury K., Adhikari B.: Letrozole Dispersed on Poly (vinyl alcohol) Anchored Maleic Anhydride Grafted Low Density Polyethylene: A Controlled Drug Delivery System for Treatment of Breast Cancer. Colloids Surf., B. 116, 169-175 (2014) https://doi.org/10.1016/j.colsurfb.2013.12.040

[30] Pan Z., Zhao B., Zhou J.: Study on the Nonlinearity Between Absorbance and Concentration of Dyes in Aqueous Solution. Lab. Res. Explor. 33, 22-26+38 (2014)

[31] Xin W.: Applicable conditions and limitations of Lambert Beer law. Chem. Ind. Times. 34, 49-51 (2020) https://doi.org/10.16597/j.cnki.issn.1002-154x.2020.07.015

[32] Shi J, Zhang H, Yu Y, et al. Adsorption properties of calcium alginate-silica dioxide hybrid adsorbent to methylene blue[J]. J. Inorg. Organomet. Polym. Mater., 30(6), 2114-2125 (2020)

\section{Competing interests}

\section{Funding}

The authors declare that no funds, grants, or other support were received during the preparation of this manuscript 


\section{Competing Interests}

The authors have no relevant financial or non-financial interests to disclose.

\section{Author Contributions}

All authors contributed to the study conception and design. Material preparation were performed by [Li Fenghong], [Lv Weisi], [Guo Keyun], [Huang Feihong], data collection and analysis were performed by [Wang Zhe], [Li Pengzhen], [Da Wei]. The first draft of the manuscript was written by [Wang Zhe] and all authors commented on previous versions of the manuscript. All authors read and approved the final manuscript.

\section{Data Availability}

All data generated or analysed during this study are included in this published article and its supplementary information files. 
Figures

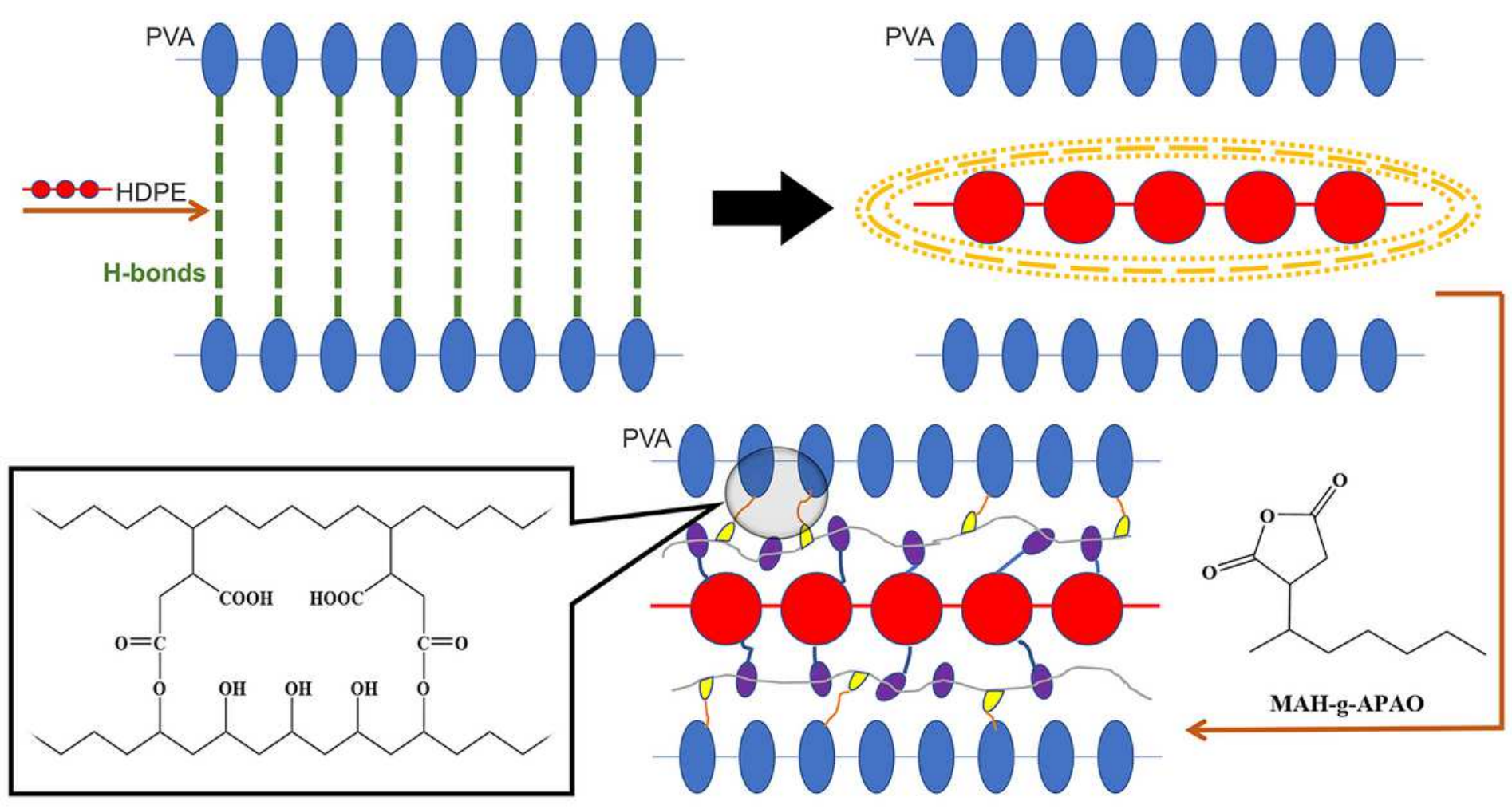

Figure 1

Legend not included with this version 


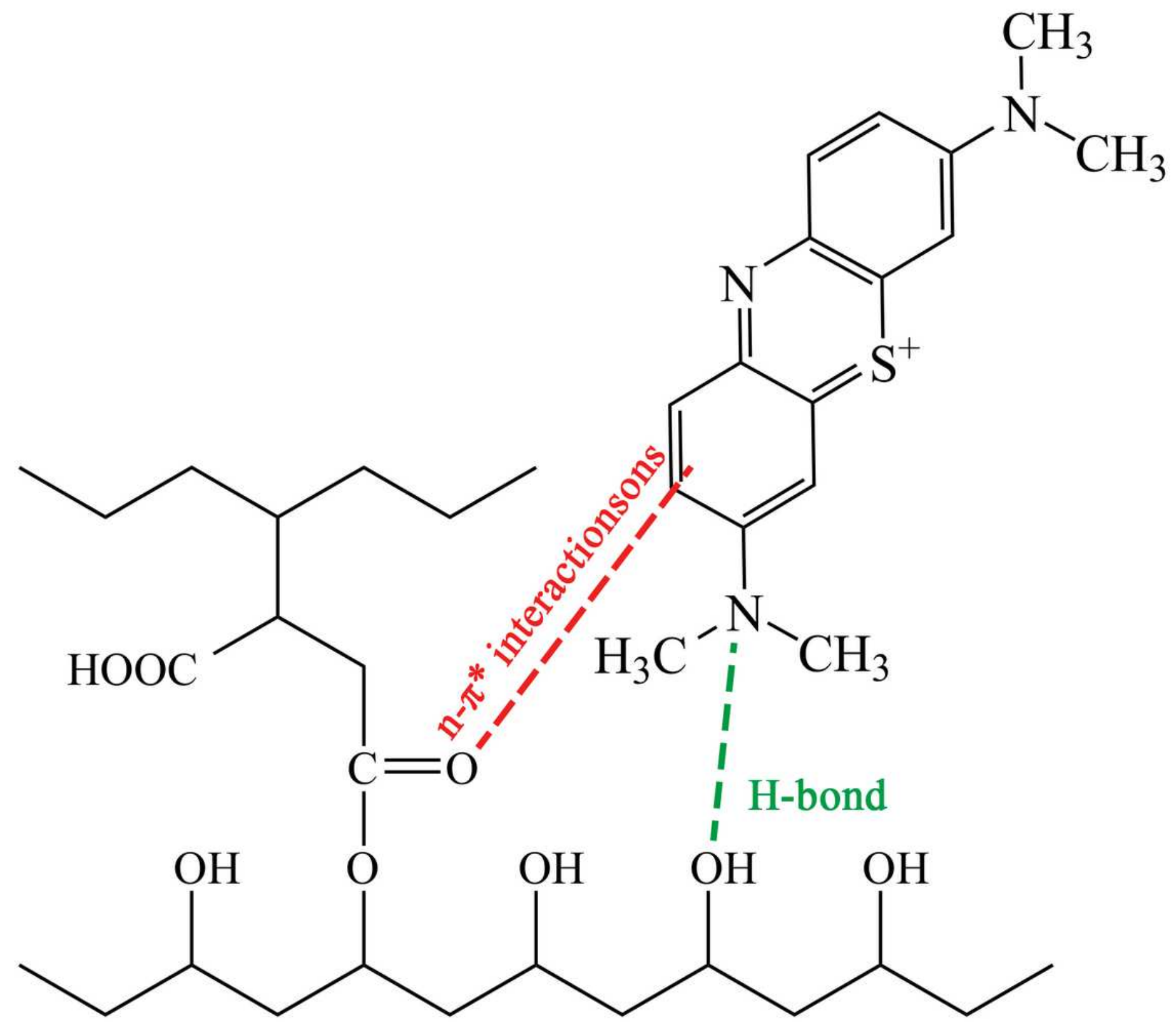

Figure 2

Legend not included with this version 

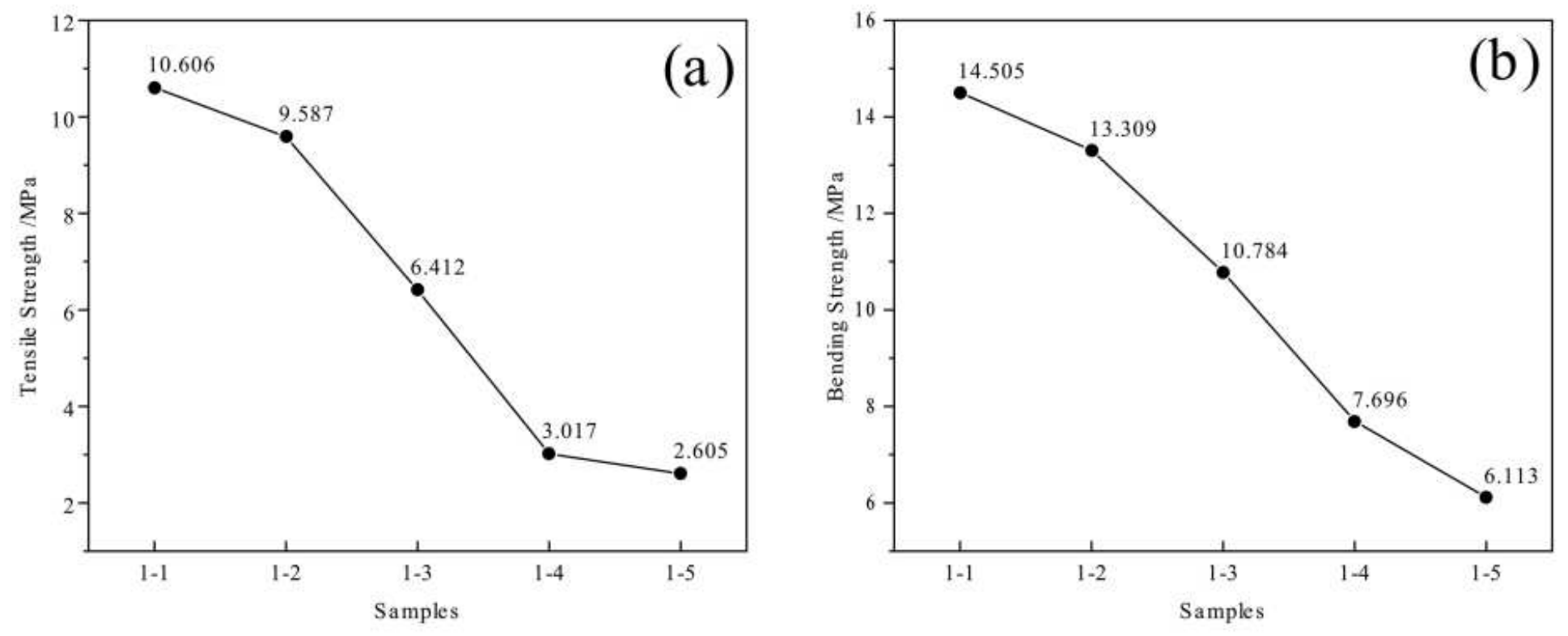

Figure 3

Legend not included with this version
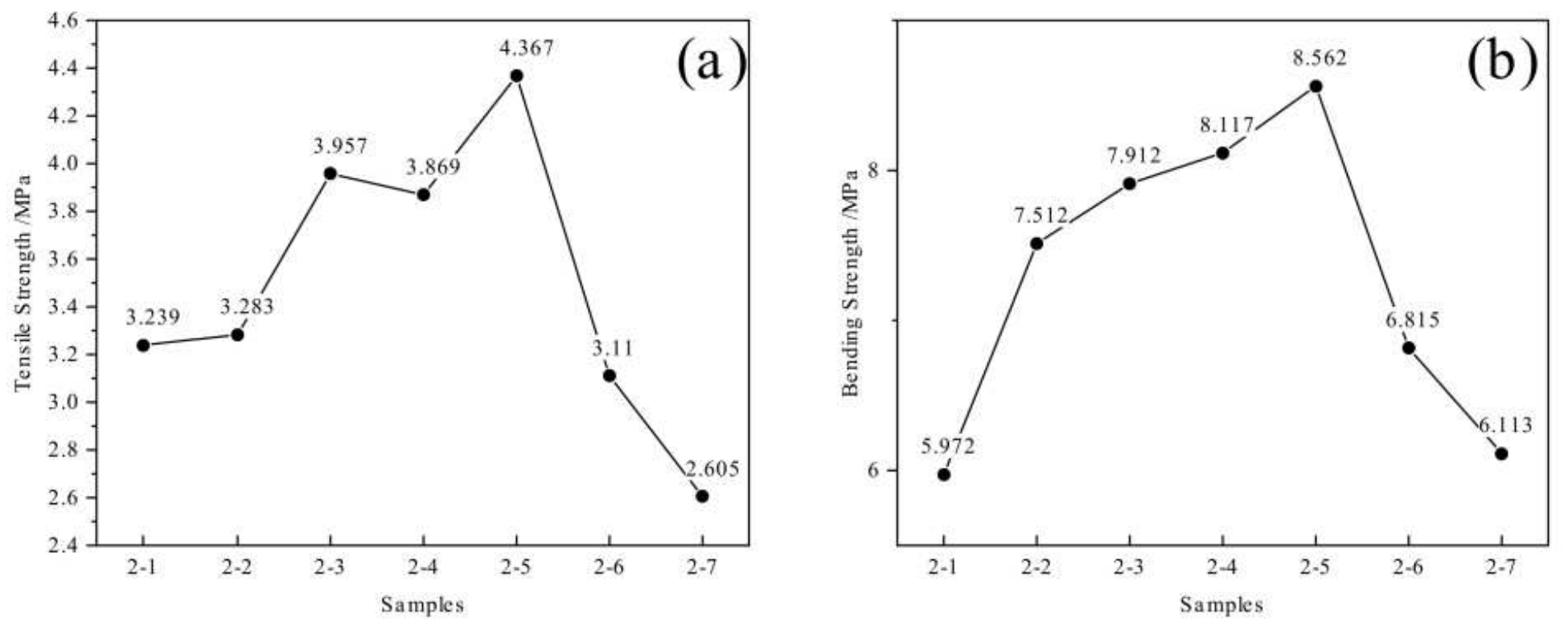

Figure 4

Legend not included with this version 

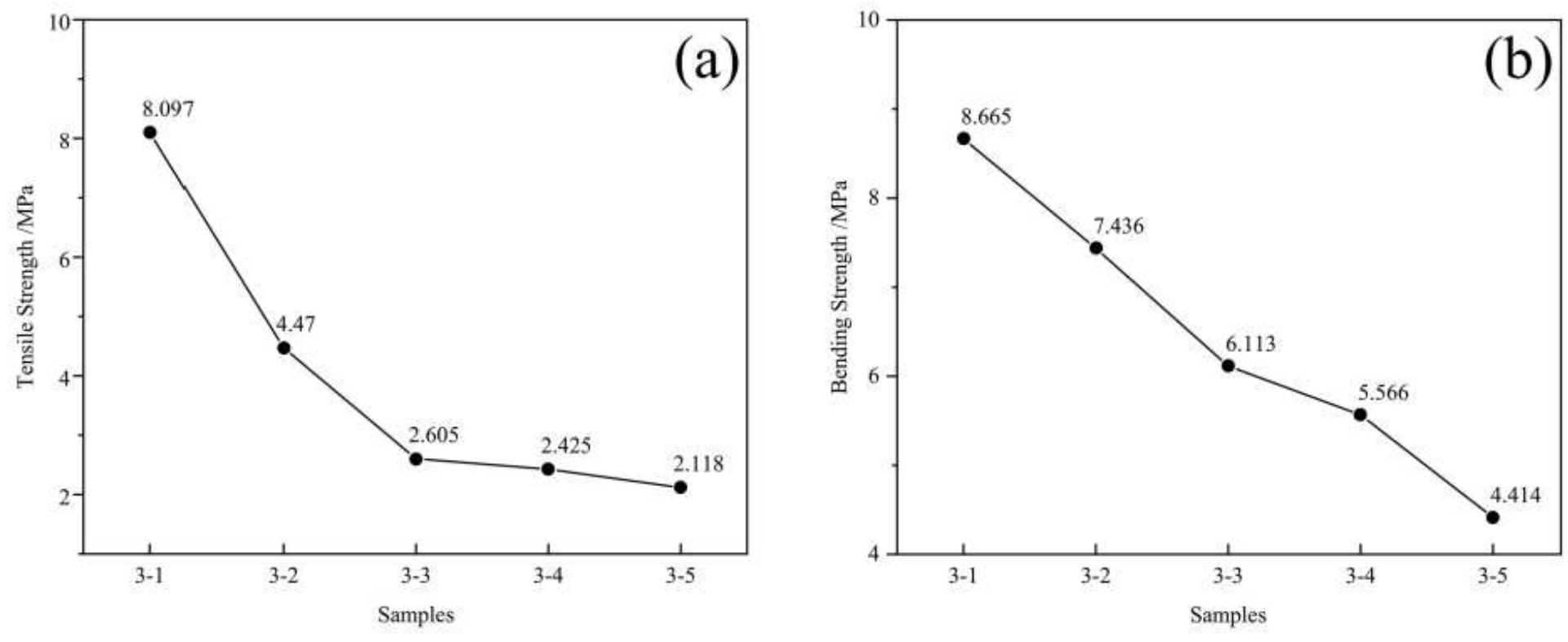

Figure 5

Legend not included with this version 


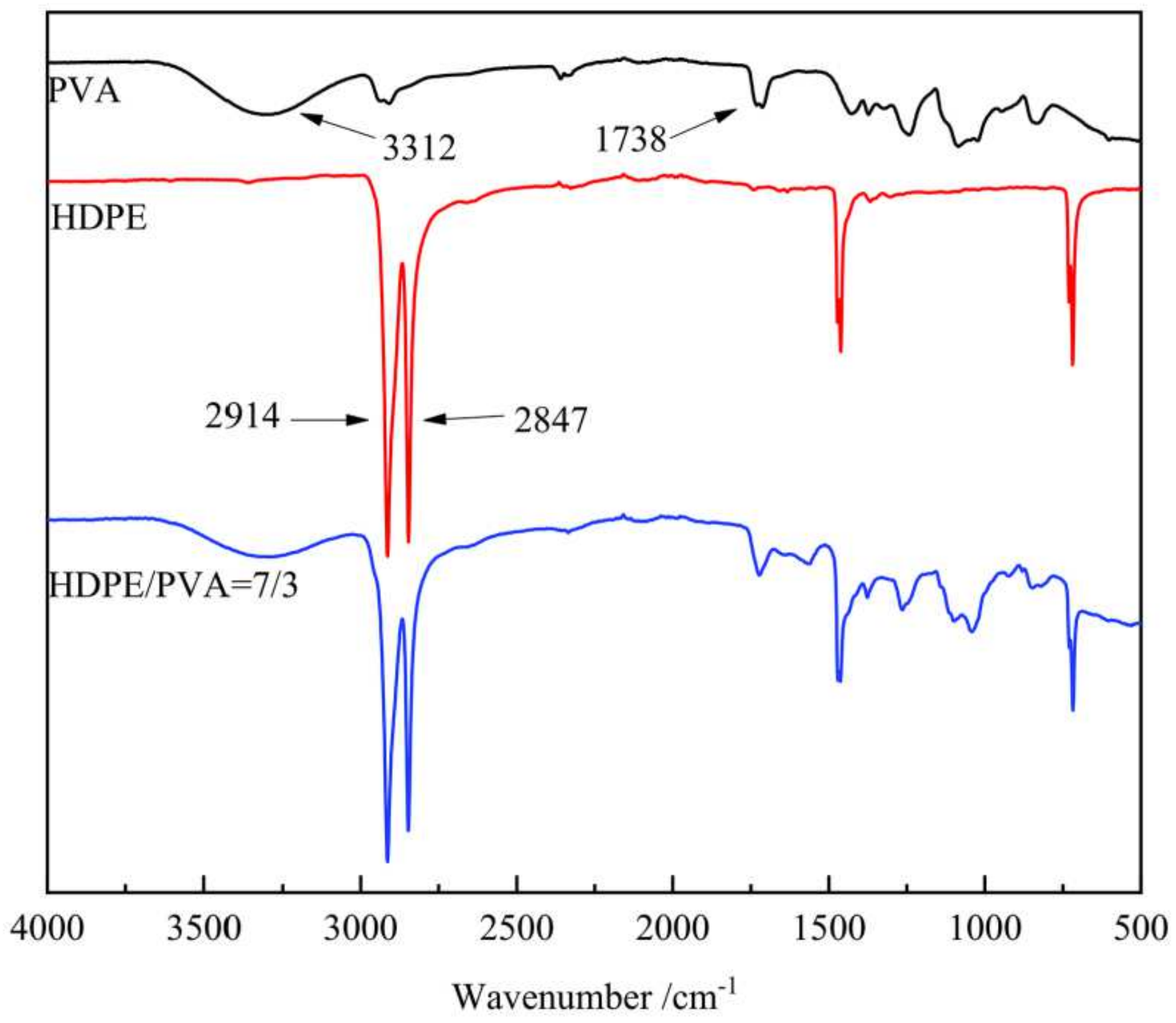

Figure 6

Legend not included with this version 


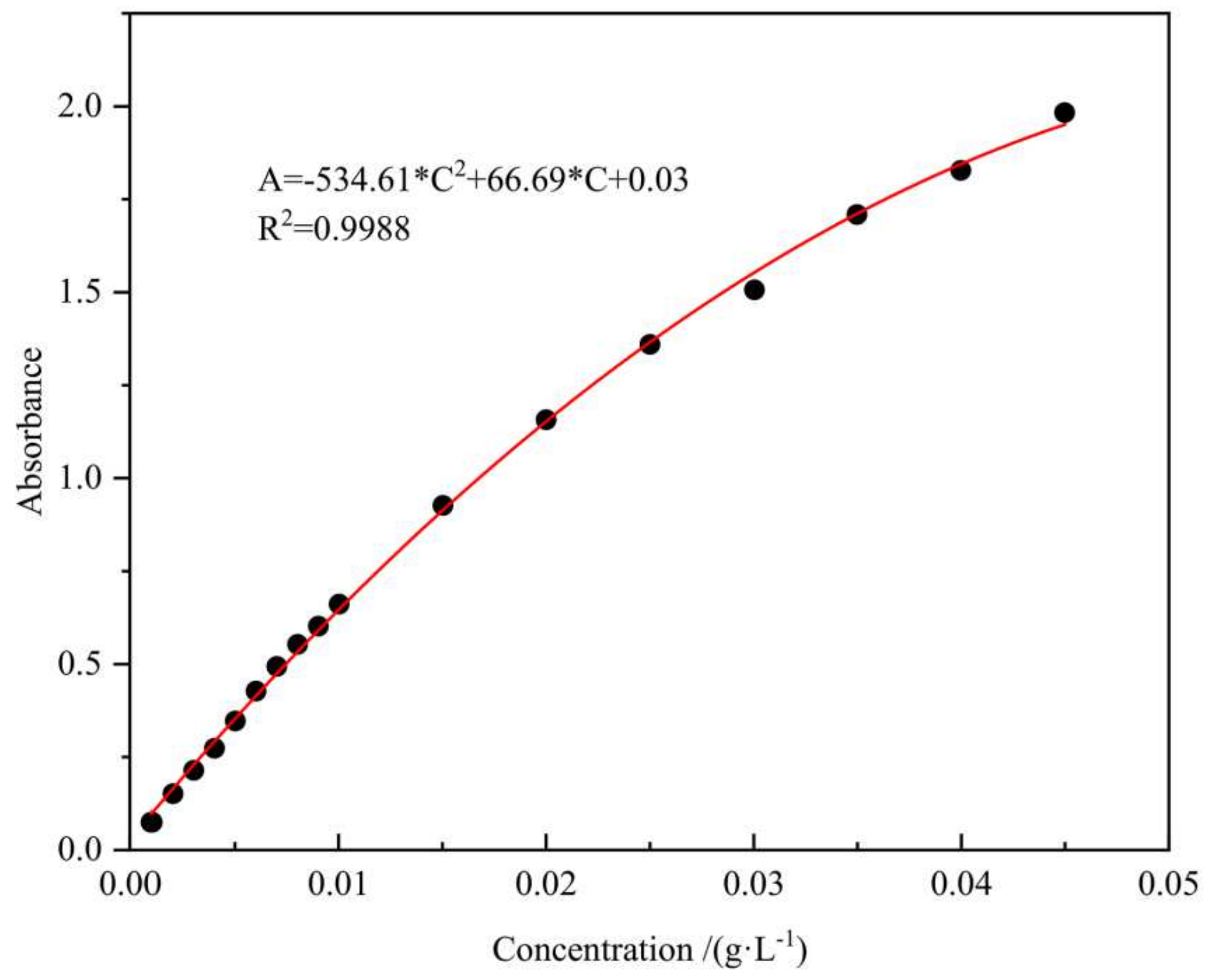

Figure 7

Legend not included with this version 


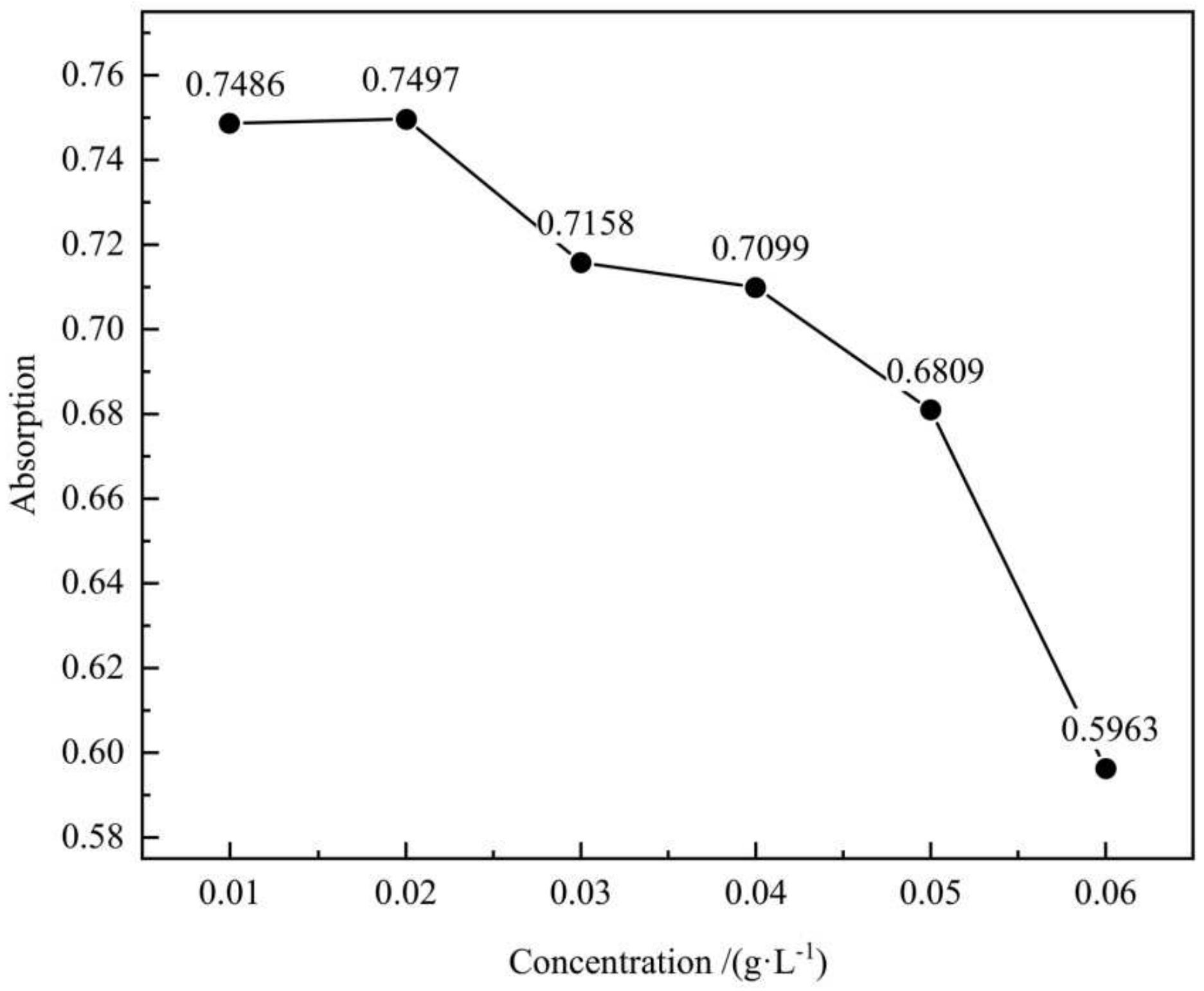

Figure 8

Legend not included with this version 


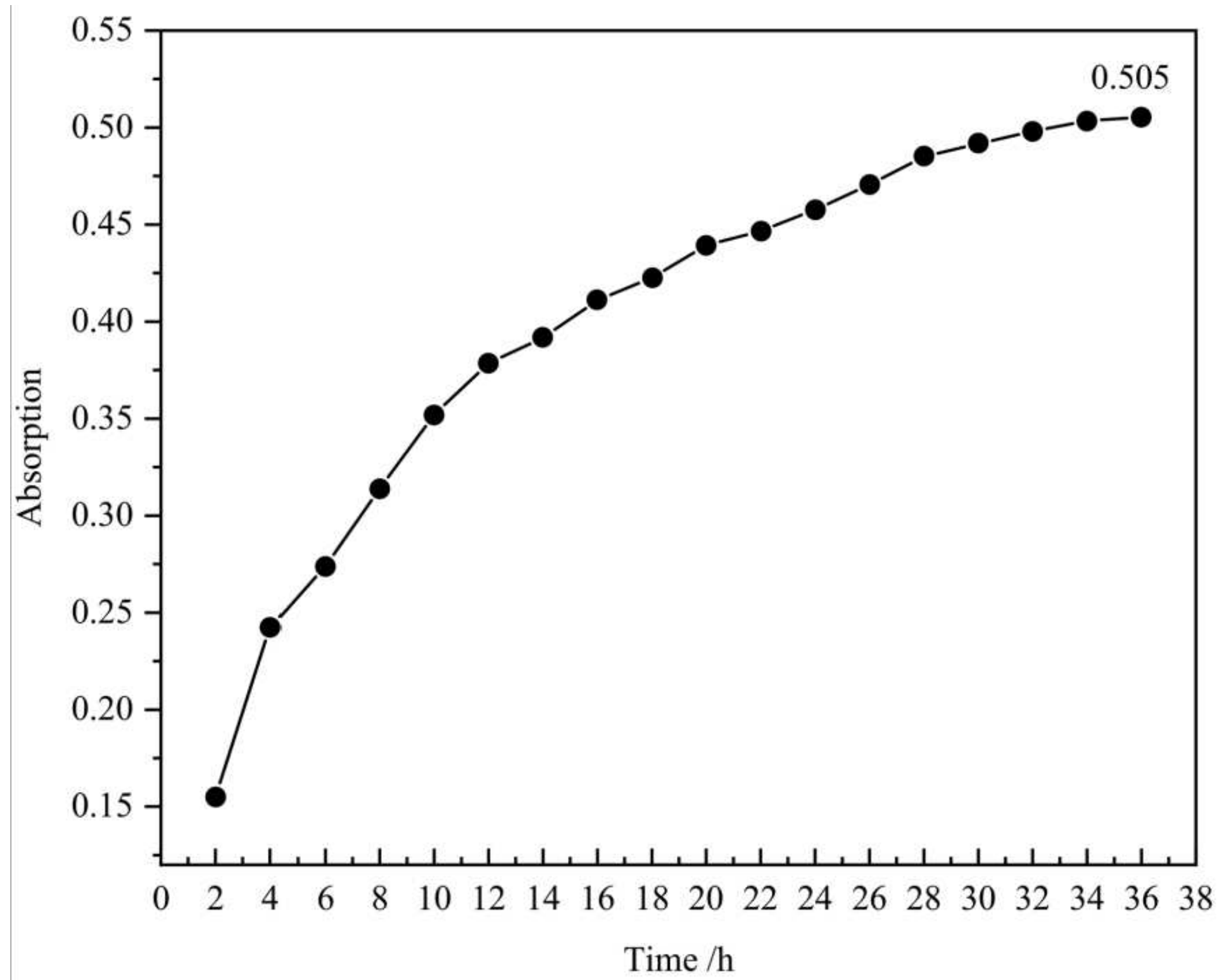

Figure 9

Legend not included with this version 


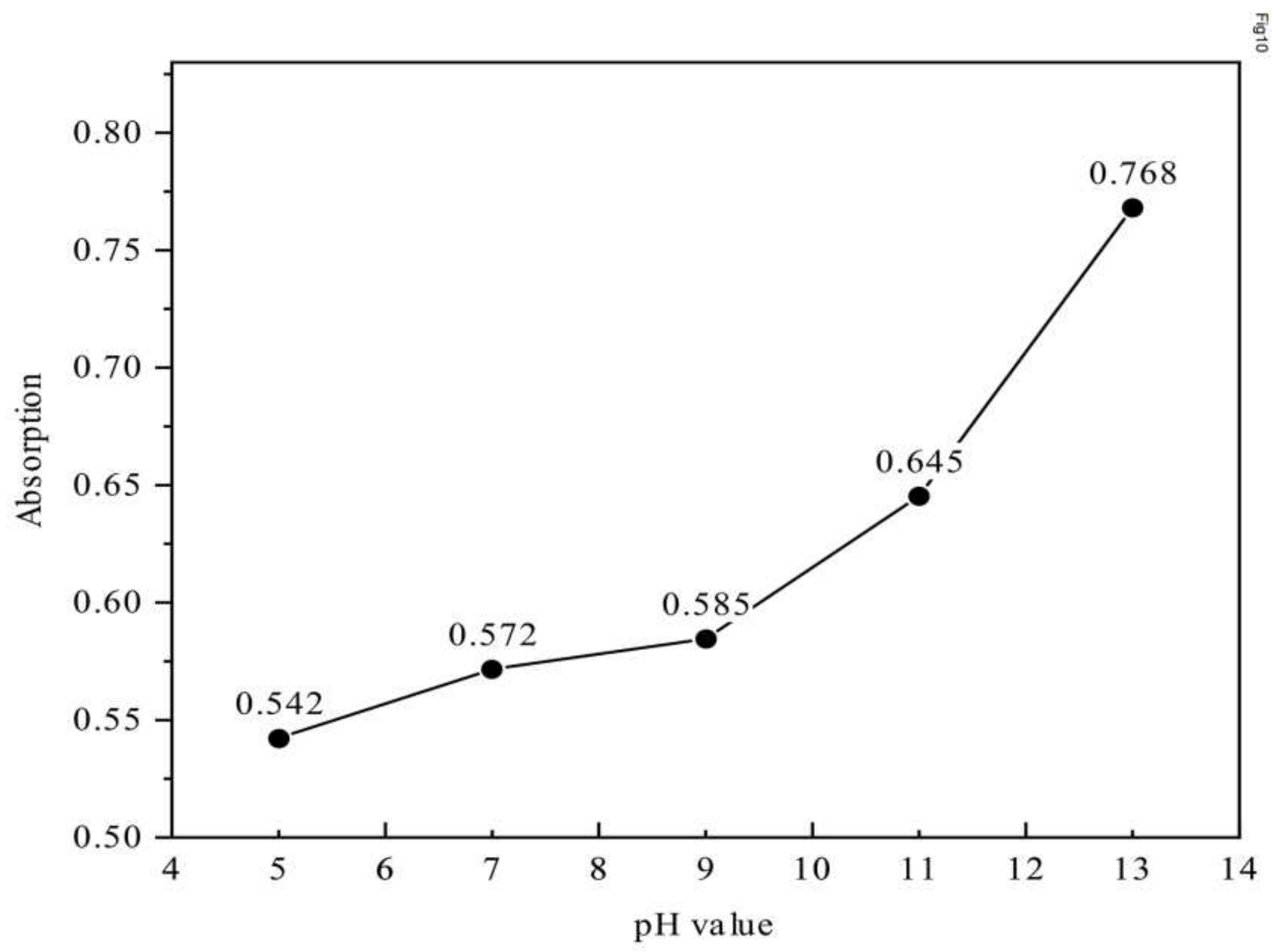

Figure 10

Legend not included with this version 

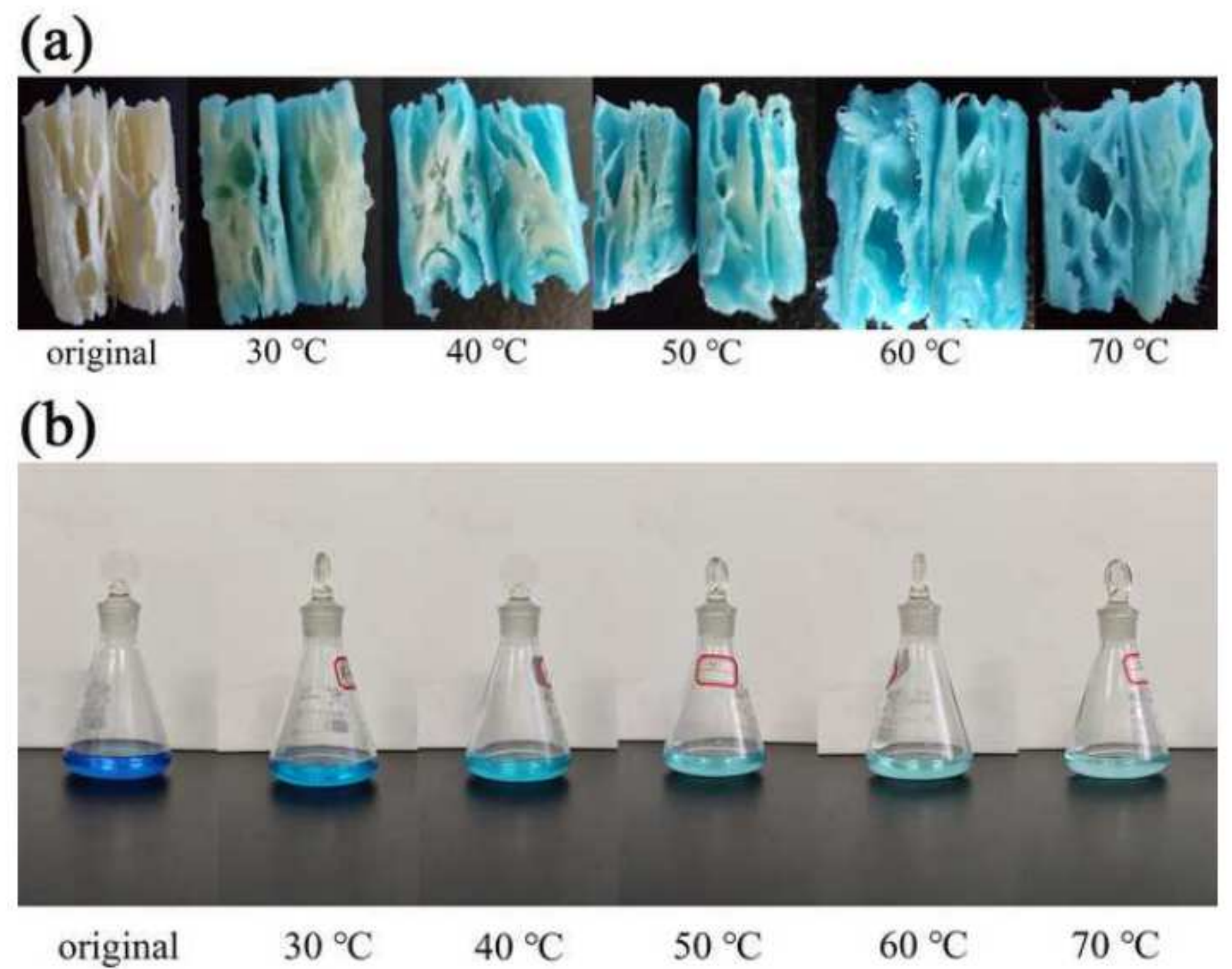

Figure 11

Legend not included with this version 

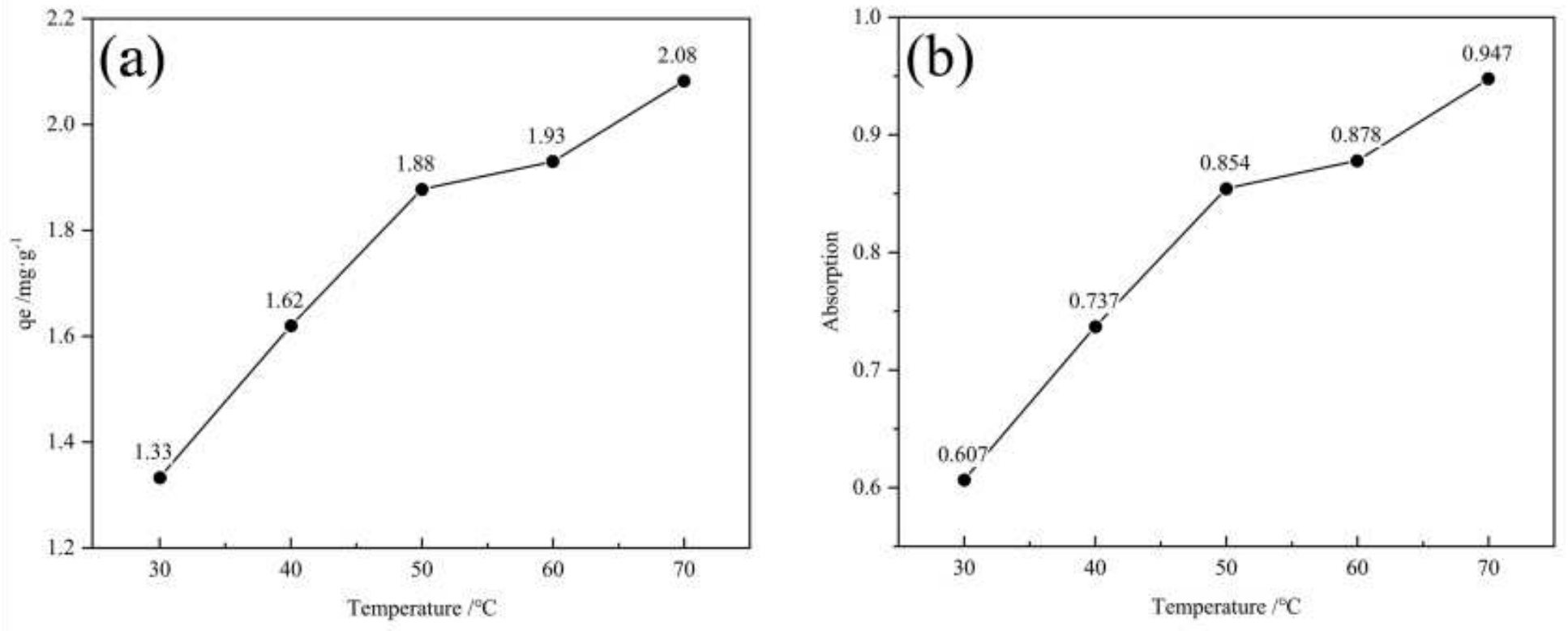

Figure 12

Legend not included with this version 


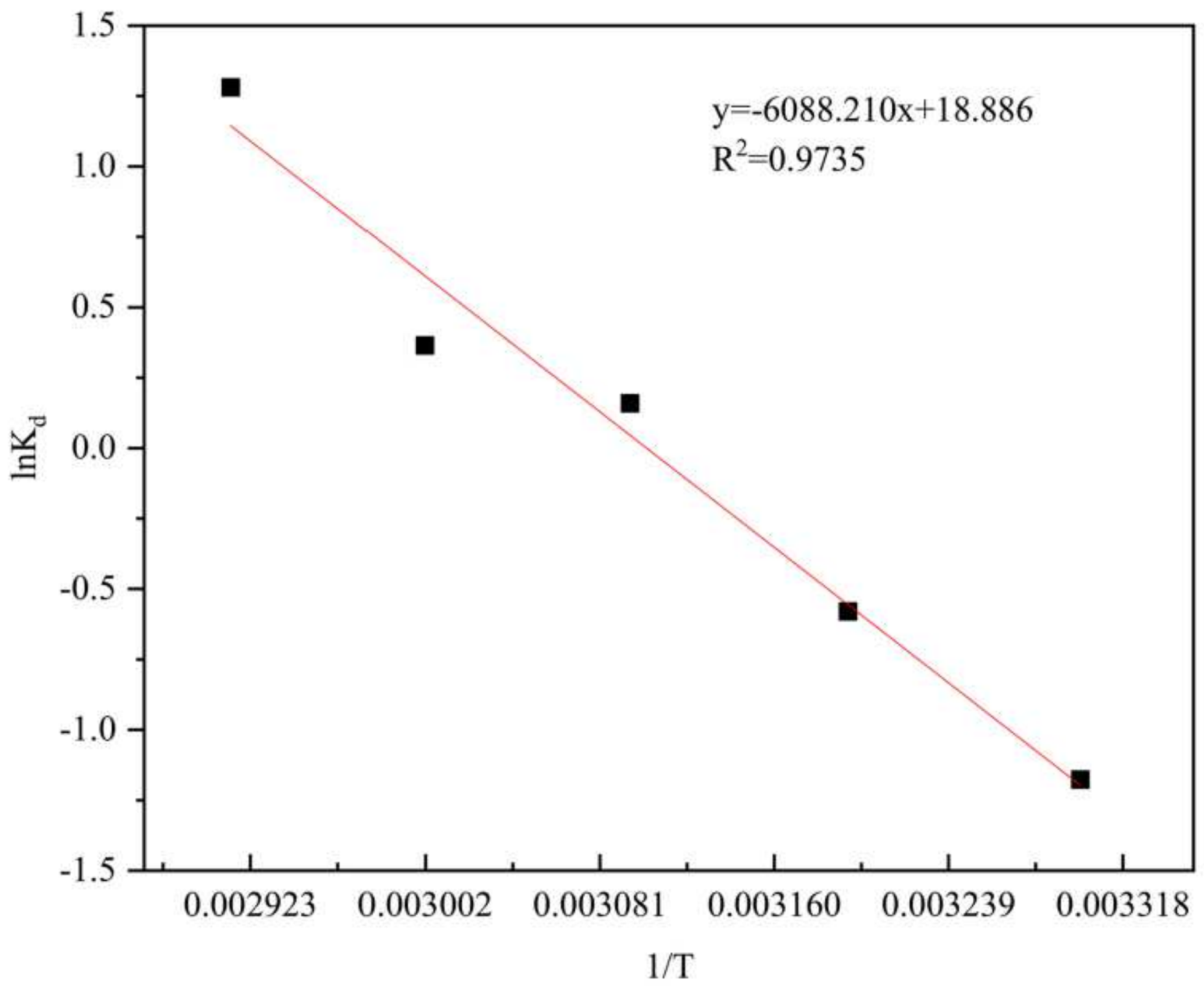

Figure 13

Legend not included with this version 